\title{
Mathilda Tomaryn Bruckner, Chrétien Continued. A Study of the Conte du Graal and its Verse Continuations
}

\section{Maria Colombo Timelli}

\section{OpenEdition}

\section{Journals}

Édition électronique

URL : http://journals.openedition.org/studifrancesi/5519

DOI : 10.4000/studifrancesi.5519

ISSN : 2427-5856

Éditeur

Rosenberg \& Sellier

\section{Édition imprimée}

Date de publication : 1 septembre 2011

Pagination : 382-383

ISSN : 0039-2944

\section{Référence électronique}

Maria Colombo Timelli, « Mathilda Tomaryn Bruckner, Chrétien Continued. A Study of the Conte du Graal and its Verse Continuations », Studi Francesi [En ligne], 164 (LV | II) | 2011, mis en ligne le 30 novembre 2015, consulté le 13 janvier 2021. URL : http://journals.openedition.org/studifrancesi/5519; DOI : https://doi.org/10.4000/studifrancesi.5519

Ce document a été généré automatiquement le 13 janvier 2021.

\section{(c) $(1)$}

Studi Francesi è distribuita con Licenza Creative Commons Attribuzione - Non commerciale - Non opere derivate 4.0 Internazionale. 


\title{
Mathilda Tomaryn Bruckner, Chrétien Continued. A Study of the Conte du Graal and its Verse Continuations
}

\author{
Maria Colombo Timelli
}

\section{RÉFÉRENCE}

MATHILDA TOMARYN BRUCKNER, Chrétien Continued. A Study of the Conte du Graal and its Verse Continuations, Oxford University Press, 2009, $263 \mathrm{pp}$.

1 «This is not a book about the Grail... though it is a book about the Story of the Grail» (p. vii): cette phrase, qui revient comme un refrain ici et ailleurs, introduit bien ce livre, qui concerne justement le Conte du Graal de Chrétien de Troyes et ses quatre Continuations, que l'A. fait dialoguer entre eux autour de cinq sujets: le jeu qui s'établit sur le nom-ou l'anonymat des auteurs concernés (chapitre 1, Authorial Relays, pp. 32-85), les rapports à l'intérieur des couples d'amants (chapitre 2, Telling Tales, of Maidens in Tents, pp. 86-115), les relations entre mères et fils (chapitre 3, Sons and Mothers, Mothers and Lovers, pp.116-148), la violence et sa légitimité dans le monde arthurien (chapitre 4, Violent Swords and Utopian Plowshares, pp. 149-186), les anomalies d'une structure complexe, comprenant un début et quatre tentatives de mener à terme l'«histoire» (chapitre 5, Middles, Beginnings, and Ends, pp.187-212). Reprenant des articles déjà publiés entre 1996 et 2006, ce volume constitue néanmoins une mise au point claire et harmonisée, et essaie de proposer une interprétation globale du «cycle» du Graal: comme elle le souligne dans une Introduction substantielle (pp. 1-31), M.T.B. estime que les questions que le roman de Chrétien laisse ouvertes de par son inachèvement refont inévitablement surface dans les Continuations, ce qui nous impose une lecture complexe, faite d'allers-retours du roman source aux œuvres qui le continuent. Par ailleurs, la transmission même de l'ensemble (cf. la table des 
manuscrits pp. 6-7) montre bien que les lecteurs du Moyen Âge avaient affaire à une suite ininterrompue, ce qui implique une dynamique d'interaction à l'intérieur d'un ensemble que la critique moderne seulement a divisé sur la base de critères externes, dont l'attribution à un auteur. Une seule remarque sur le corpus adopté: pourquoi avoir exclu les deux pseudo-prologues Elucidation et Bliocadran (sauf erreur, ils ne sont que cités en abrégé en tant que transmis dans le ms. de Mons, p.6)? Si sur le plan du contenu ceux-ci ne constituent certainement pas des «continuations» au sens propre, il est établi qu'ils le sont bien sur le plan chronologique, leur composition se situant au XIII ${ }^{\mathrm{e}}$ siècle, et que leur transmission dans ce manuscrit les insère à plein titre dans la matière graalienne. L'Introduction fait aussi une large part aux énigmes posés par le Conte du Graal - incongruités, énigmes, contradictions - qui obligent en quelque sorte les «continuateurs» (ainsi que les critiques d'aujourd'hui) à se confronter continuellement avec le texte source; parallèlement, comme le souligne la Conclusion (pp. 213-227), les Continuations jettent une nouvelle lumière sur le texte-matrice, en essayant - sans doute en vain - d'en résoudre les mystères.

2 Parmi les annexes et compléments, il faut signaler la bibliographie (pp. 237-254) et l'index nominum et rerum (pp. 255-263). 